\title{
PENGARUH KONSENTRASI KATALIS DAN REUSABILITY KATALIS PADA SINTESIS TRIASETIN DENGAN KATALISATOR LEWATIT
}

\author{
Lucky Wahyu Nuzulia Setyaningsih ${ }^{1}$, Umi Mei Rizkiyaningrum ${ }^{2}$, Risky Andi ${ }^{3}$ \\ Jurusan Teknik Kimia, Fakultas Teknologi Industri, Universitas Islam Indonesia ${ }^{1,2,3)}$ \\ Jl Kaliurang Km. 14,5 Sleman, Yogyakarta 55584 \\ E-mail:lucky.nuzulia@uii.ac.id ${ }^{l}$
}

\begin{abstract}
Triacetin is a product from reaction between glycerol and acetic acid on acid catalyst. The use of solid catalysts such as ion exchange Lewatit is an alternative method to ease product separation. Synthesize of triacetin was conducted in a batch reactor with stirring speed of $175 \mathrm{rpm}$, at temperarture of $100^{\circ} \mathrm{C}$ and the reactant ratio of 6 mole acetic acid / glycerol. The effect of concentration catalyst and reusability of catalyst were investigated. The highest conversion obtained for $84,84 \%$ in catalyst concentration $5 \%$ to weight of glycerol. The result showed that comparison of catalyst concentration give real effect to the conversion of glycerol into triacetin, while the reusability catalyst does not give a significant effect on glycerol conversion be triacetin.
\end{abstract}

Keywords : Glycerol, Lewatit, Triacetin, Bio - Additive Fuel.

\section{PENDAHULUAN}

Gliserol merupakan hasil samping dari proses pembuatan biodiesel melalui reaksi transesterifikasi trigliserida dalam minyak nabati. Gliserol yang dihasilkan sekitar 10\% (berat) dari produksi biodiesel (Knothe, dkk, 2005). Semakin meningkatnya produksi biodiesel akan diikuti dengan peningkatan jumlah gliserol sebagai hasil samping reaksi transesterifikasi, oleh sebab itu gliserol perlu diolah menjadi produk turunannya untuk meningkatkan nilai ekonominya. Salah satu produk turunan gliserol adalah triasetin, triasetin dapat dimanfaatkan sebagai bahan aroma makanan, pelarut pada parfum, plastisizer untuk resin, dan dapat juga digunakan sebagai zat aditif dalam bahan bakar cair untuk mengurangi knocking pada mesin (Nuryoto, dkk., 2010). Penggunaan triasetin sebagai zat aditif dinilai sangat menjanjikan karena triasetin berasal dari bahan baku yang terbarukan dan ramah lingkungan.

Triasetin dapat dihasilkan melalui proses esterifikasi gliserol, dimana gliserol direaksikan dengan asam organik maupun asam anorganik untuk membentuk gliserol ester (Abdurrakhman, 2013). Reaksi esterifikasi dapat dilangsungkan dengan bantuan katalis asam dan reaksinya bersifat reversible. Tanpa keberadaan asam kuat, reaksi esterifikasi akan berjalan sangat lambat, tetapi akan mencapai kesetimbangan dalam waktu singkat ketika asam kuat dan alkohol berada dalam sistem reaksi bersama (Fessenden \& Fessenden, 1982).

\subsection{Faktor - faktor yang Mempengaruhi Reaksi Esterifikasi.}

- Suhu Reaksi

Esterifikasi adalah reaksi reversible (dapat balik), sehingga suhu akan berpengaruh terhadap konstanta kesetimbangan kimia.

- Waktu Reaksi

Waktu reaksi berpengaruh dalam reaksi esterifikasi. Dalam industri, waktu reaksi diinginkan sependek mungkin dengan yield produk yang tinggi guna mengurangi biaya operasi.

- Perbandingan Pereaksi

Naiknya perbandingan mol reakstan akan mempercepat laju reaksi, sehingga konversi reaktan membentuk produk akan semakin besar.

- Pengadukan

Pengadukan bertujuan untuk memperbesar peluang tumbukan antar 
molekul-molekul pereaksi, hal ini akan mempercepat terjadinya reaksi.

- Katalisator

Keberadaan katalis dalam suatu reaksi akan meningkatkan laju reaksi. Meskipun katalis berpengaruh terhadap kecepatan reaksi, namun katalis tidak ikut bereaksi dan tidak mengalami perubahan secara kimiawi pada akhir reaksi. Selain itu, katalisator juga berfungsi untuk menurunkan energi aktivasi. Jika jumlah katalisator dinaikkan, maka energi aktivasi akan turun, sehingga laju reaksi akan meningkat.

\subsection{Katalisator}

Berdasarkan fasenya, katalisator dapat dibagi menjadi dua jenis yaitu katalisator homogen dan katalisator heterogen. Katalisator homogen memiliki fase yang sama dengan bahan pereaksinya, sedangkan katalisator heterogen memiliki fase yang berbeda dengan fase pereaksinya. Katalisator heterogen memiliki kelebihan pada proses pemisahan dan recycle yang lebih mudah dan murah daripada katalisator homogen.

Beberapa jenis katalis yang dapat digunakan dalam reaksi esterifikasi antara lain, katalis asam cair, katalis asam padat, katalis enzim dan katalis ion exchange resin. Penggunaan asam sebagai katalis harus diimbangi dengan penggunaan reaktan yang berlebih, karena berdasarkan prinsip $L e$ Chatelier, penambahan reaktan akan menggeser reaksi ke arah produk.

Pada penggunaan enzim sebagai katalis, kerja enzim adalah untuk mengkatalis proses hidrolisis dari lemak dan minyak, sehingga peran enzim dalam reaksi esterifikasi adalah pada metabolisme lemak. Salah satu enzim yang sering digunakan dalam reaksi esterifikasi adalah lipase, yang memiliki kemampuan untuk mengarahkan pembentukan senyawa tertentu.

Pada penggunaan katalis asam padat, katalis harus memiliki sifat hidrofobik, sehingga air yang terbentuk dalam reaksi esterifikasi tidak ikut masuk ke dalam katalis.

\subsection{Katalis Lewatit}

Katalis lewatit yang digunakan pada penelitian ini merupakan katalis padat yang termasuk ke dalam jenis resin penukar ion dengan kekuatan asam sangat kuat. Katalis ini berbentuk butiran yang dapat digunakan sebagai katalisator asam heterogen dalam berbagai reaksi organik. Resin kation menyediakan acid site yang dibutuhkan sebagai katalisator dalam sintesis gliserol asetat. Penggunaan resin kation sebagai katalisator memiliki kelebihan yaitu selektivitas reaksinya tinggi, permukaan bersifat asam, proses pemisahannya mudah karena tidak larut dalam larutan reaksi dan mudah diregenerasi sehingga dapat digunakan berulang kali. Meskipun demikian, katalis ini juga memiliki kelemahan, yaitu air dapat masuk ke dalam katalis sehingga akan menggangu proses protonasi asam karboksilat (asam lemak). Katalis Lewatit memiliki suhu operasi maksimum $120^{\circ} \mathrm{C}$, jika katalis digunakan pada suhu diatas suhu operasinya, maka katalis akan mengalami deaktivasi, sehingga pada penelitian ini suhu operasi reaksi dijalankan pada $100^{\circ} \mathrm{C}$.

\subsection{Sintesis Triasetin}

Penggunaan katalis jenis resin ion exchanger pada reaksi sintesis triasetin melalui reaksi esterifikasi antara gliserol dan asam asetat juga dilakukan oleh beberapa peneliti. Nuryoto (2011) mereaksikan 1 gmol gliserol dengan 7 gmol asam asetat untuk menghasilkan triasetin, penelitian dilakukan dalam reaktor batch dengan kecepatan pengadukan $1000 \mathrm{rpm}$, suhu reaksi $100^{\circ} \mathrm{C}$, katalisator yang digunakan adalah Indion 225 $\mathrm{Na}$ dengan ukuran diameter katalis $0,085 \mathrm{~cm}$, konsentrasi katalisator yang didapatkan pada penelitian ini untuk menghasilkan konversi optimum sebesar $41,7 \%$ pada waktu 90 menit adalah $3 \%$ berat asam asetat.

Gelosa dkk. (2003) melakukan penelitian dengan menggunakan katalis Amberlyst-15 sebesar 15 massa resin / massa gliserol, didapatkan konversi tertinggi diperoleh pada suhu $373 \mathrm{~K}$, perbandingan pereaksi 3,9 gmol 
asam asetat / gmol gliserol yaitu sebesar $50 \%$.

Pada penelitian ini akan dilakukan proses sintesis triasetin melalui reaksi esterifikasi dengan bahan baku gliserol dan asam asetat menggunakan katalis lewatit. Penggunaan katalis lewatit dimaksudkan untuk mempermudah proses pemisahan hasil reaksi (Choi dkk., 1996). Selain itu, pemanfaatan katalis lewatit yang merupakan resin penukar ion diharapkan mampu memberi bahan alternatif pendukung pengembangan produk turunan gliserol.

Pengaruh konsentrasi katalis pada reaksi sintesis triasetin akan dianalisa dengan melakukan percobaan dengan variasi konsentrasi katalis 2\%, 3\% dan 5\% berat gliserol. Untuk mempelajari stabilitas katalis lewatit, katalis yang telah digunakan akan digunakan kembali pada reaksi selanjutnya. Pemakaian berulang dilakukan sebanyak 2 kali dan 3 kali pemakaian.

\section{BAHAN DAN PENELITIAN}

\subsection{Bahan}

Bahan yang digunakan dalam penelitian ini adalah gliserol $\left(\mathrm{C}_{3} \mathrm{H}_{5}(\mathrm{OH})_{3}\right)$ dengan kemurnian $99 \%$ dan massa jenis 1,2483 $\mathrm{g} / \mathrm{mL}$. Asam asetat $\left(\mathrm{CH}_{3} \mathrm{COOH}\right)$ dengan kemurnian 99,8\% dengan rapat massa 1,05 $\mathrm{g} / \mathrm{mL}$. Katalisator Lewatit dengan densitas $1,28 \mathrm{~g} / \mathrm{mL}$ yang memiliki gugus fungsi asam sulfonic dan nilai kapasitas penukar kation (KPK) sebesar 1,8636 mek/g.

\subsection{Metode Penelitian}

\subsubsection{Preparasi Katalis}

Katalis lewatit diaktivasi dengan menggunakan larutan $\mathrm{HCl} 1 \mathrm{~N}$ sebanyak $200 \%$ dari volum katalis. Campuran katalis diaduk menggunakan magnetic stirer selama 30 menit, kemudin dibilas dengan aquadest hingga $\mathrm{pH}$ netral.

\subsubsection{Sintesis Triasetin}

Alat dirangkai seperti pada Gambar 1. Gliserol dengan volume tertentu serta katalis lewatit dipanaskan di dalam labu leher tiga, sedangkan asam asetat dipanaskan di tempat terpisah. Setelah suhu kedua reaktan mencapai suhu reaksi, asam asetat dimasukkan dalam labu leher tiga yang berisi gliserol dan katalis. Selama reaksi berlangsung dilakukan pengadukan dengan kecepatan $175 \mathrm{rpm}$ dan suhu dijaga konstan sesuai suhu reaksi.

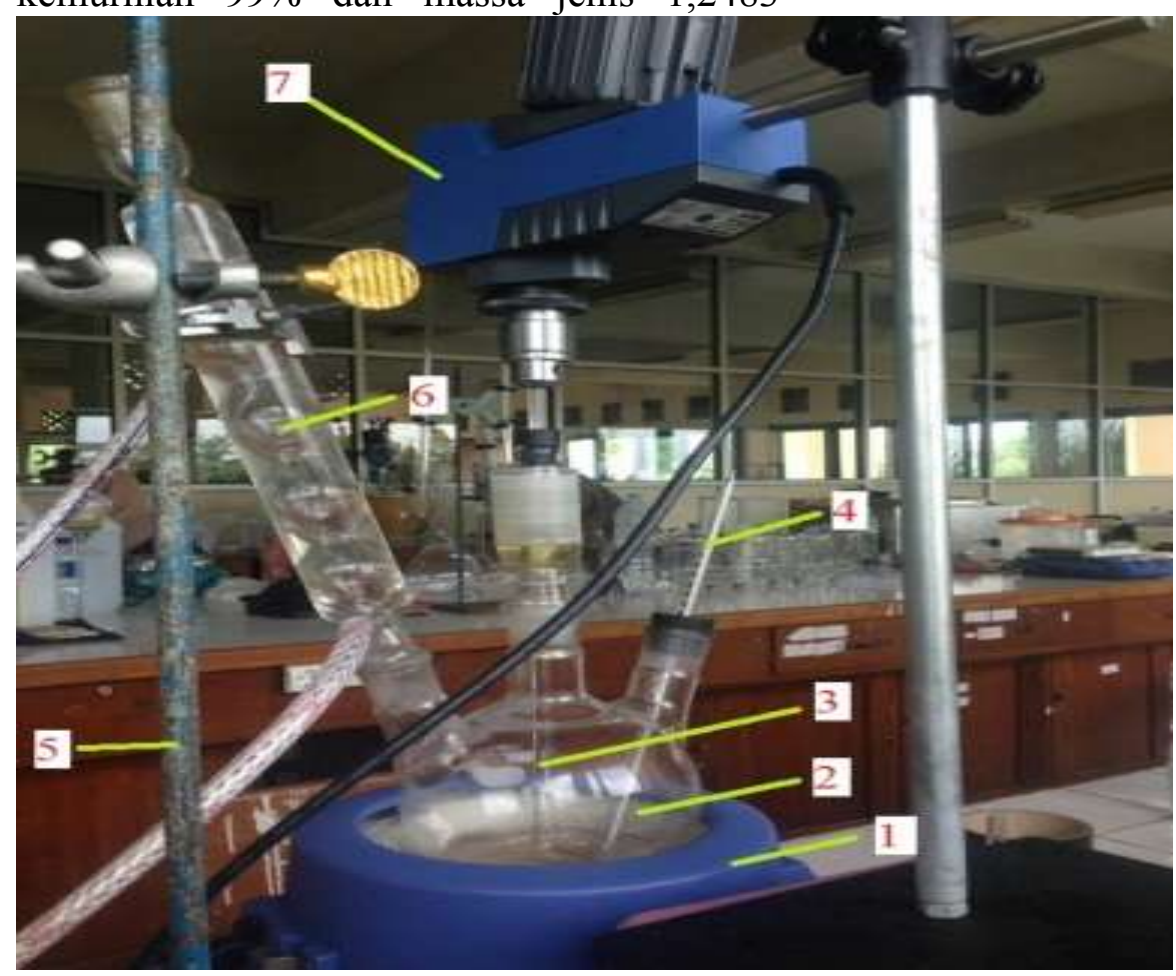

Gambar 1. Rangkaian Alat. $\underline{\text { Keterangan : }}$

1. Pemanas Mantel.

2. Labu Leher Tiga.

3. Pengaduk Merkuri.

4. Thermometer.

5. Statif dan Klem.

6. Pendingin Balik.

7. Motor Pengaduk. 
Tabel 1. Konversi Gliserol pada berbagai Persen Berat Katalis

\begin{tabular}{c|c|c|c|c}
\hline \multirow{2}{*}{$\begin{array}{c}\text { Waktu } \\
\text { (menit) }\end{array}$} & \multicolumn{3}{|c|}{ Konversi Gliserol (\%) } & \\
\cline { 2 - 5 } & Katalis 2\% & Katalis 3\% & Katalis 5\% & Katalis 7\% \\
\hline 0 & 0 & 0 & 0 & 0 \\
15 & 74,40 & 74,69 & 83,7 & 82,78 \\
30 & 76,31 & 78,78 & 84,84 & 81,11 \\
45 & 75,55 & 78,8 & 81,39 & 82,95 \\
60 & 77,69 & 77,95 & 83,97 & 83,35 \\
75 & 77,12 & 79,24 & 83,17 & 83,78 \\
90 & 73,65 & 81,35 & 83,15 & 83,21 \\
\hline
\end{tabular}

Keterangan, $\mathrm{t}=0$ adalah sesaat setelah katalis ditambahkan.

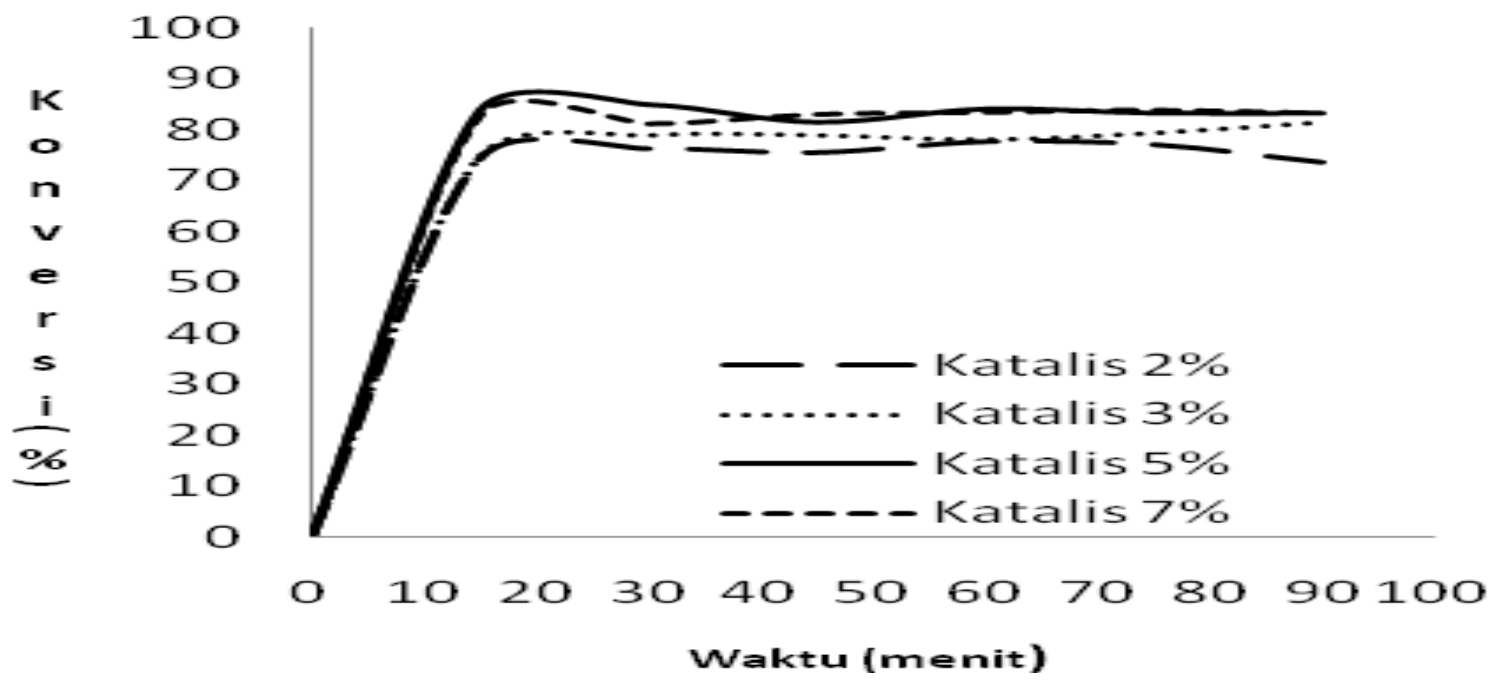

Gambar 2. Hubungan antara Konversi Gliserol dan Waktu pada Berbagai Persen Berat Katalis.

\subsubsection{Variabel Penelitian}

Penelitian

dilakukan dengan memvariasikan persen berat katalis $(2 \%, 3 \%$, $5 \%$ dan $7 \%$ berat gliserol), suhu reaksi $100^{\circ} \mathrm{C}$, rasio mol reaktan gliserol dan asam asetat $1: 6$ serta kecepatan pengadukan 175 rpm. Katalis yang telah digunakan, akan digunakan kembali sebanyak 2 kali dan 3 kali pemakaian untuk menganalisa stabilitas katalis. Sampel diambil setiap 15 menit dan reaksi dijalankan selama 90 menit.

\subsubsection{Analisis Hasil}

Data yang diperoleh dari penelitian berupa kadar gliserol bebas pada setiap interval waktu 15 menit yang diperoleh pada tiap - tiap kondisi proses.
Data ini selanjutnya digunakan untuk mengevaluasi nilai konversi sebagai fungsi waktu. Kadar gliserol dapat dihitung dengan rumus sebagai berikut :

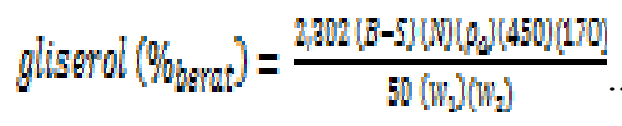

Dengan :

$\mathrm{B}=$ Volume titrasi $\mathrm{Na}_{2} \mathrm{~S}_{2} \mathrm{O}_{3}$ untuk larutan blangko (ml).

$\mathrm{S}=$ Volume titrasi $\mathrm{Na}_{2} \mathrm{~S}_{2} \mathrm{O}_{3}$ untuk larutan sampel (ml).

$\mathrm{N}=$ Normalitas larutan $\mathrm{Na}_{2} \mathrm{~S}_{2} \mathrm{O}_{3}$.

$\rho_{a}=$ Densitas aquadest $(\mathrm{g} / \mathrm{mL})$.

$w_{1}=$ Berat sampel awal (g).

$w_{2}=$ Berat sampel pengenceran $(\mathrm{g})$. 
Tabel 2. Perbandingan Hasil Penelitian Sintesis Triasetin pada Berat Katalis Optimumnya Menggunakan Katalis Resin

\begin{tabular}{c|c|c|c}
\hline Peneliti & Katalis & Berat Katalis & Konversi \\
\hline Penelitian ini & Lewatit & $5 \%$ & $84,84 \%$ \\
Nuryoto (2011) & Indion $225 \mathrm{Na}$ & $3 \%$ & $41,7 \%$ \\
Gelosa, dkk. (2003) & Amberlyst-15 & $15 \%$ & $50 \%$ \\
Luque dkk. (2008) & Starbon-400- $\mathrm{SO}_{3} \mathrm{H}$ & 0,2 gram & $99 \%$ \\
\hline
\end{tabular}

3. HASIL DAN PEMBAHASAN

\subsection{Pengaruh Konsentrasi Katalis}

Nilai konversi yang didapat dari setiap percobaan akan dibandingkan untuk mengetahui pengaruh kenaikan berat katalis terhadap konversi gliserol. Hubungan antara konversi dan waktu pada berbagai persen berat katalis disajikan pada Tabel 1 dan Gambar 2.

Dari tabel 1 dan gambar 1 terlihat bahwa nilai konversi gliserol menjadi triasetin melalui reaksi esterifikasi semakin meningkat dengan meningkatnya konsentrasi katalis atau persen berat katalis yang digunakan. Penelitian yang dilakukan oleh Rastegari (2015) menunjukkan hal yang serupa, dimana dengan meningkatnya konsentrasi katalis, maka konversi cenderung meningkat.

Kecenderungan yang teramati dari Gambar 1 adalah pada peningkatan berat katalisator dari $2 \%$ hingga $5 \%$ terjadi kenaikan konversi yang cukup signifikan. Sedangkan pada peningkatan berat katalisator dari 5\% ke 7\% kenaikan konversi tidak terlalu signifikan, meskipun grafik yang dihasilkan mengalami fluktuasi namun secara umum dapat disimpulkan bahwa tidak ada perbedaan signifikan antara berat katalisator $5 \%$ dan 7\%. Dengan demikian dapat diambil kesimpulan bahwa berat katalisator 5\% merupakan berat katalis optimum.
Dari percobaan yang dilakukan, konversi tertinggi diperoleh pada persen berat katalis 5\% dengan konversi sebesar $84,84 \%$, sedangkan konversi terendah diperoleh pada persen berat katalis $2 \%$ dengan konversi sebesar 73,65\%. Fenomena lain yang terlihat dari Gambar 1 adalah kenaikan konversi gliserol sebagai fungsi waktu cukup landai dan fluktuatif. Hal ini disebabkan karena jumlah situs aktif yang tersedia pada katalis hampir mendekati jumlah maksimum yang dibutuhkan oleh reaktan.

Hal serupa juga ditunjukkan pada penelitian yang dilakukan oleh Yadav (2012) dimana pada persen berat katalis 5\% terlihat bahwa konversi tidak mengalami peningkatan dibanding dengan penggunaan katalis $3 \%$ berat. Hal ini mungkin disebabkan karena pada berat katalis 5\% tidak terjadi pencampuran yang sempurna yang disebabkan karena kerapatan padatan katalis di dalam larutan cukup besar sehingga mengurangi bidang kontak antara katalis dan reaktan.

Selain itu, dengan tingginya konsentrasi padatan dalam larutan memungkinkan terjadinya dead zone di dalam reaktor. Jagadeeswariah (2010) menyatakan bahwa dengan sedikit jumlah katalis yang mencukupi digunakan maka konversi maksimum dapat tercapai. Berbeda dengan selektivitas yang tidak terlalu terpengaruh oleh perubahan berat katalis yang digunakan. Hasil penelitian ini dapat dibandingkan dengan penelitian terdahulu seperti yang terlihat pada tabel 2 diatas. 
Tabel 3. Konversi Gliserol pada Beberapa Kali Penggunaan Katalis

\begin{tabular}{c|c}
\hline Pemakaian & Konversi Gliserol (\%) \\
\hline 1 kali & 73,65 \\
3 kali & 73,07 \\
\hline
\end{tabular}

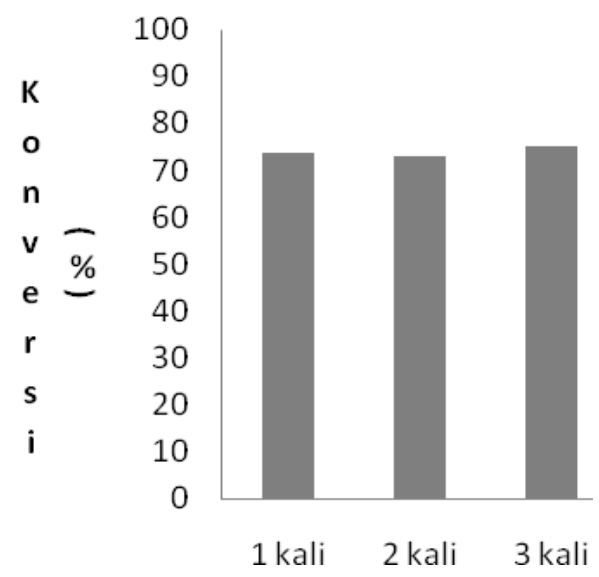

Gambar 3. Konversi Gliserol pada Beberapa Kali Penggunaan Katalis.

\subsection{Reusability Katalis}

Untuk mempelajari stabilitas katalis dan pengaruh penggunaan berulang katalis, katalis Lewatit akan digunakan sampai tiga kali pemakaian, dengan beberapa variable dijaga konstan, yaitu suhu operasi $100^{\circ} \mathrm{C}$, rasio mol reaktan gliserol/asam asetat 1:6, waktu reaksi 90 menit dan berat katalis $2 \%$. Setelah digunakan untuk reaksi, katalis hanya dicuci dengan menggunakan aquades suhu ruang tanpa melalui perlakuan apapun. Data konversi gliserol pada menit ke 90 pada beberapa kali penggunaan katalis dapat dilihat pada tabel 3 dan gambar 3.

Dari tabel 3 dan gambar 3 terlihat bahwa reaktivitas atau kemampuan katalistor lewatit dalam mengkatalis reaksi sintesis triasetin cenderung konstan meski telah digunakan sampai tiga kali pemakaian. Dari pemakaian pertama ke pemakaian kedua, terjadi sedikit penurunan nilai konversi namun pada pemakaian ketiga terjadi sedikit kenaikan nilai konversi. Pada akhir reaksi konversi yang didapatkan pada pemakaian pertama adalah 73,65\%, kemudian turun menjadi $73,07 \%$, namun kembali naik menjadi $74,05 \%$ pada pemakaian ketiga.
Hal serupa juga ditemukan pada penelitian yang dilakukan oleh Zhu, dkk. (2013). Hasil yang didapat menunjukkan bahwa reaktivitas katalis $\mathrm{HSiW} / \mathrm{ZrO}_{2}$ cenderung konstan hingga empat kali pemakaian. Menurut Shanhui, stabilitas penggunaan berulang $\mathrm{HSiW} / \mathrm{ZrO}_{2}$ disebabkan karena stabilitas hidrolitiknya pada kondisi asam yang cukup tinggi. Selain itu stabilitas katalis juga didukung oleh tingginya jumlah situs asam yang terdapat di dalam katalis, sehingga akan mencegah terjadinya pelepasan komponen aktif selama penggunaan berulang.

Gao (2015) melaporkan hal serupa, dimana katalis Graphene Oxide (GO) yang telah di-recovery dapat digunakan secara berulang hingga empat kali pemakaian tanpa terjadi penurunan aktivitas katalis dan hasil FTIR menunjukkan bahwa struktur katalis tidak mengalami perubahan dan gugus oksigen di dalam katalis tetap terjaga selama reaksi berlangsung. Stabilitas dari katalis Lewatit pada reaksi esterifikasi gliserol dapat disebabkan karena sifat heterogen alami yang dimiliki katalis dapat mendukung untuk pemulihan / recovery katalis itu sendiri. 


\section{KESIMPULAN}

Dari percobaan dan pembahasan yang telah dilakukan dapat ditarik kesimpulan bahwa:

1. Kecenderungan yang teramati dari penelitian dengan variasi persen berat katalis adalah nilai konversi gliserol menjadi triasetin melalui reaksi esterifikasi semakin meningkat dengan meningkatnya konsentrasi katalis atau persen berat katalis yang digunakan. Berdasarkan hasil penelitian ini, berat katalis optimum yang dipilih adalah 5\% berat gliserol.

2. Dari hasil data yang diperoleh dapat disimpulkan bahwa reaktivitas atau kemampuan katalistor lewatit dalam mengkatalis reaksi sintesis triasetin cenderung konstan meski telah digunakan sampai empat kali pemakaian.

\section{DAFTAR PUSTAKA}

Abdurrakhman, Rifianto, Y., \& Widayat, 2013. Studi Awal Proses Pembuatan Glycerol dan Asam Benzoat dengan Menggunakan Katalis Asam Klorida. Jurnal Teknologi Kimia dan Industri, 2, 30-36.

Choi, J.I., Hong, W.H., \& Cham, H.N, 1996, Reaction Kinetics of Lactic Acid with Methanol Catalyzed by Acid Resins, Int. J. Chem. Kinet., 28, 3741.

Fessenden, R.J. \& Fessenden, J.S., 1986, Kimia Organik, Edisi Ketiga, Jilid 2, Erlangga.

Gao, X., Zhu, S., \& Li, Y., 2015, Graphene oxide as a facile solid acid catalyst for the production of bioadditives from glycerol esterification, Catalysis Communication, 62, 4851.
Gelosa, D., Ramaioli, M., Valente, G., and

Morbidelli, $\quad$ M., 2003

Chromatographic Reactors:

Esterification of Glycerol with

Acetic Acid Using Acidic Polymeric Resins, Ind. Eng. Chem. Res., 42, 6536-6544.

Jagadeeswaraiah, K., Balaraju, M., Sai Prasad, P., S., \& Lingaiah, N., Selective Esterification of Glycerol to Bioadditives over Heteropoly Tungstate Supported on Cscontaining Zirconia Catalyst, Applied Catalysis A: General, 386, 166-170.

Knothe, G., Van Gerpen J., \& Krahl, J. 2005. Encyclopedia of Chemical Technology, (3 ${ }^{\text {rd }}$ ed.), vol. 11, p.921, John Wiley \& Sons, New York.

Luque R., Budarin V., Clark J. H. and Macquarrie D. J., 2008, Glycerol Transformations on Polysaccharide Derived Mesoporous Material, Appl. Catal. B: Environ., 82, 157162.

Nuryoto, Sulistiyo, H., Sri Rahayu, S., dan Sutijan 2010, Esterifikasi Gliserol dan Asam Asetat dengan Katalisator Indion $225 \mathrm{Na}$, Seminar Nasional Perkembangan Riset dan Teknologi di Bidang Industri ke-16, PSIT UGM, Yogyakarta.

Rastegari, H., Hassan, S., \& Ghaziaskar, 2015, From Glycerol as The ByProduct of Biodiesel Production to Value-added Monoacetin by Continuous and Selective Esterfication in Acetic Acid, Journal of Industrial and Engineering Chemistry, 21, 856861.

Zhu, Shanhui., Gao, X., G., Fang, D., Zhu, Y., Hongyan, Z., \& Li, Y., 2013. Design of a highly active silverexchanged phosphotungstic acid catalyst for glycerol esterification with acetic acid, Journal of Catalysis, 306, 155-163. 